\title{
La omnipotente blancura: el tratamiento de los Derechos Civiles en el cine norteamericano de Hollywood. Tres ejemplos paradigmáticos de éxito comercial
}

\author{
Guess Who's Coming to Dinner | Stanley Kramer | 1967 \\ Mississippi Burning | Alan Parker| 1988 \\ The Help | Tate Taylor | 2011 \\ Javier Cossalter*
}

CONICET - Universidad de Buenos Aires

Recibido: 9 de diciembre 2017; aceptado: 22 de octubre 2018

\begin{abstract}
Resumen
La presencia de la comunidad afroamericana en el cine norteamericano data desde los inicios del cinematógrafo. No obstante, la relación entre la representación del blanco y del negro en la pantalla fue siempre desigual. Con el correr del tiempo Hollywood ha vislumbrado una evolución en las formas de aproximación a los derechos de los negros dentro de sus films. Sin embargo, esta pretendida política inclusiva manifiesta, de modo subyacente, una sólida raíz segregacionista. El propósito de este artículo consiste en analizar tres films de diferentes épocas en torno a la temática de los Derechos Civiles, realizados en Hollywood por cineastas blancos, para examinar cómo a través de diversas estrategias el hombre blanco se posiciona en un lugar de poder. Tanto Guess Who's Coming to Dinner (Stanley Kramer, 1967) como Mississippi Burning (Alan Parker, 1988) y The Help (Tate Taylor, 2011) son películas de gran éxito comercial que abordan las problemáticas de los negros desde un supuesto enfoque revalorizador pero que en el fondo sostienen un fuerte espíritu racista.
\end{abstract}

Palabras clave: Hollywood | blancos y negros | derechos civiles | racismo

The omnipotent whiteness: the treatment of Civil Rights in the American Hollywood cinema.

Three paradigmatic examples of commercial success

\begin{abstract}
The presence of the African-American community in North American cinema dates back of the beginning of the seventh art. However, the relationship between the representation of whites and blacks on the screen was always uneven. With the passing of time Hollywood has seen an evolution in the forms of approach to the rights of blacks in their films. However, this alleged inclusive policy manifests, in an underlying way, a solid segregationist root. The purpose of this article is to analyze three films from different eras concerning the issue of Civil Rights, made in Hollywood by white filmmakers, to examine how, through different strategies, the white man positions himself in a place of power. Guess Who's Coming to Dinner (Stanley Kramer, 1967), Mississippi Burning (Alan Parker, 1988) and The Help (Tate Taylor, 2011) are commercially successful films that address the problems of blacks from a supposedly revalorizing approach but that deep down they hold a strong racist spirit.
\end{abstract}

Key words: Hollywood | whites and blacks | civil rights | racism

\section{Introducción}

Prácticamente desde los comienzos del cine norteamericano la relación entre blancos y negros fue tomando forma en la pantalla. Recordemos el temprano film de Edwin S. Porter Uncle Tom's Cabin (1903) donde aparece el primer personaje negro. Sin embargo, ya desde los inicios, la posición, el valor y los privilegios de unos y (no) de otros resultaron diferentes. El primer postulado es claro: los negros no podían representarse a sí mismos siendo interpretados por actores blancos enmascarados. Luego, los actores negros pasaron a encarnar únicamente el papel de criados -estereotipo/reflejo de la realidad social que persistió con el correr del tiempo- y personajes con cualida-

javiercossalter@gmail.com 
des marcadas que visibilizaban la supuesta inferioridad de este. The Birth of a Nation (David Wark Griffith, 1915), película emblemática que sienta las bases del lenguaje cinematográfico clásico, es un claro ejemplo ya que construye una imagen totalmente negativa del negro, exhibiéndolo como un ser ignorante, violento y depravado. Pero, ¿qué es lo que lleva a esta desigualdad que escapa ampliamente a los confines del arte cinematográfico? Diferentes disciplinas intentaron avalar y/o comprender el racismo, entendido este como una valoración discriminatoria que suscita consecuencias de orden socio-cultural. De un lado, por ejemplo, la corriente denominada darwinismo socialsostiene la segregación de minorías a partir de un determinismo biológico. Ciertas condiciones genéticas permitirían distinguir razas superiores y razas inferiores; razas civilizadas y razas salvajes. ${ }^{1}$ Por otro lado, la psicología concibe este carácter de exclusión como una problemática inherente al hombre, a la cual debe renunciar para vivir en sociedad. Dicho de otra manera, "la inclinación agresiva es, por tanto, una disposición pulsional del ser humano, en la cual la cultura encuentra un enorme obstáculo" (Michel Fariña, 2002, p. 137). ${ }^{2}$

No obstante, sin desconocer las teorías mencionadas, a los fines de este trabajo resulta más apropiado encarar el racismo desde un enfoque que combine la discusión ética con la perspectiva ideológica. Como bien expresa Richard Dyer: "As long as race is something only applied to nonwhite peoples, as long as white people are not racially seen and named, they/we function as a human norm. Other people are raced, we are just people" (1997, p. 1) [Mientras que la raza sea algo sólo aplicado a personas no-blancas, mientras que los blancos no sean vistos y nombrados desde una perspectiva racial, ellos / nosotros funcionan / funcionamos como una norma humana. Otras personas son racializadas, nosotros somos sólo personas]. ${ }^{3}$ Es decir que la blancura aprehendida como norma, en tanto punto cero de comparación, se convierte en una estructura de dominación. Desde esta postura, la blancura se transforma en una categoría invisible e indivisible y por tal motivo, "white people, unable to see their particularity, cannot take account of other people's; white people create dominant images of the world and don't quite see that they thus construct the world in their own image" (1997, p. 9) [La gente blanca, incapaz de ver su particularidad, no puede tomar en cuenta la de los demás; la gente blanca crea imágenes dominantes del mundo y no ve que así construye el mundo a su propia imagen].

El cine norteamericano consolidó su imperio a partir de los años treinta y continuó su desarrollo transfiguran- do a cada paso la relación entre blancos y negros en los distintos períodos. Ahora bien, la propuesta que aquí presentamos entiende que la aparente evolución en el tratamiento de la negritud en el cine de Hollywood conforme pasan las décadas -inclusión de actores negros, temáticas a favor de la lucha contra el racismo, etc.- revela sin embargo, de modo conservador y naturalista, focos de pretendida supremacía del ser blanco. O dicho con otras palabras, la omnipresencia del falso mesías liberal blanco. En este sentido, el presente trabajo está centrado en la revisión del tópico de los Derechos Civiles en el cine norteamericano en tres momentos diversos teniendo en cuenta tres films de éxito comercial dirigidos por cineastas blancos, ${ }^{4}$ a la luz del postulado esbozado anteriormente. El corpus escogido es el siguiente: Guess Who's Coming to Dinner (Stanley Kramer, 1967); ${ }^{5}$ Mississippi Burning (Alan Parker, 1988); ${ }^{6}$ The Help (Tate Taylor, 2011). ${ }^{7}$ La aceptación del público, la legitimación de la Academia y la repercusión positiva en el campo de la crítica convierten a estos films en ejemplos paradigmáticos sobre cómo el cine puede reflejar y promover a la vez un patrón ideológico colectivo -el racismo- que se mantiene latente y vigente en la sociedad en la que se inscribe.

De este modo, el análisis hará hincapié en ciertas premisas que sostienen y confirman la hipótesis planteada: la tolerancia falaz del blanco en el primer film, la acción suprema de los blancos y el ocultamiento de la verdadera lucha en el segundo, la acción concientizadora del blanco dentro de la lucha del negro en el tercero. La metodología de aproximación a las películas devela una doble lectura-somera, por un lado e implícita por el otro- cuya articulación y deconstrucción permite evidenciar tanto el punto de vista ideológico hegemónico y encubierto de la industria del cine más influyente del mundo ${ }^{8}$ como también la problemática ética acerca de la representación social -y audiovisual- de las minorías; en este caso, la comunidad afroamericana.

\section{Anti-racismo racista: a propósito de Guess Who's Coming to Dinner}

De los tres films seleccionados este es el único que aborda de modo tangencial el tópico de los derechos civiles. Sin embargo, el contexto de producción de la película -fines de los años sesenta- coincide con la fase de mayor productividad del Movimiento por los Derechos Civiles en Estados Unidos. Se considera tradicionalmente que este período comienza con el boicot a los autobu- 
ses de Montgomery en 1955 y termina con el asesinato de Martin Luther King Jr. en 1968, aunque la lucha por los derechos del afroamericano en dicho país continúa de muchas otras formas hasta nuestros días.

Ahora bien, como dijimos, el relato se vincula de cierta manera con la lucha consignada anteriormente: superficialmente el film pone en juego el tabú racial del romance entre un hombre negro y una mujer blanca. En esta misma línea de apreciación inicial, y en palabras de Hernán Vera y Andrew Gordon, "the dramatic tension is between bigotry and racial tolerance" $(2003$, p. 85$)$ [La tensión dramática es entre el fanatismo y la tolerancia racial]. Sin embargo, como examinaremos a continuación, el tema central refiere a una reafirmación de la supremacía del blanco -que en este caso gracias a su decencia y su tolerancia resuelve el conflicto- antes que a un tratamiento crítico respecto del verdadero conflicto sobre el matrimonio interracial en los Estados Unidos de finales de la década del sesenta.

Atendamos rápidamente al argumento: la historia se nuclea en torno al regreso de Joanna Drayton a su hogar en San Francisco, quien trae a su nuevo novio el Dr. John Prentice, un hombre negro -físico e idealista-, con el propósito de presentarlo en la cena a sus padres, Matt -un editor de periódicos reconocido por su liberalismo ferviente- y su mujer Christina -dueña de una galería de arte- para comunicarles su futuro casamiento. En principio, y luego de verificar el "curriculum" de Prentice -línea de análisis que trabajaremos luego-, Christine y Matt no tienen prejuicios y no se muestran en contra del matrimonio por racismo, pero intentarán convencer a Joanna de que no se case por los problemas que ello les ocasionaría en la sociedad norteamericana de la época. Los padres de Prentice también muestran cierto descontento con la apresurada decisión. John ha decidido que si hay alguna objeción, él no ha de llevar a cabo el matrimonio. Finalmente, gracias a la aprobación última de Matt se resuelve el conflicto de forma positiva.

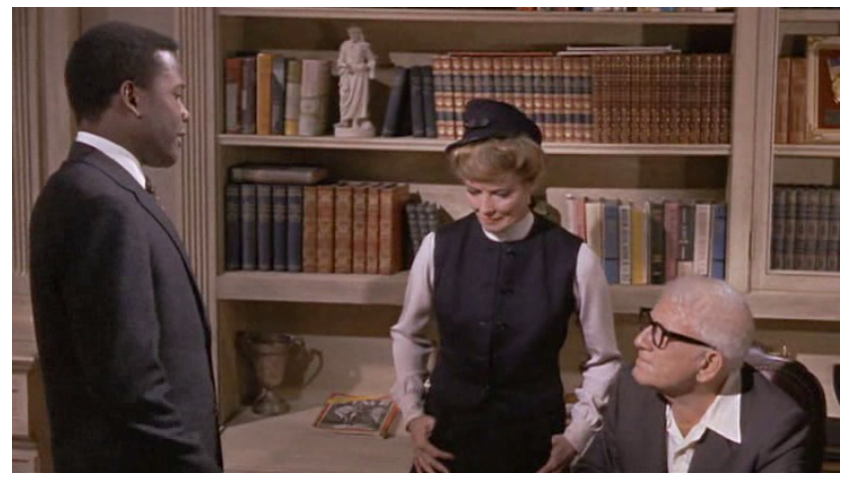

De este modo, y continuando con esta primera perspectiva de carácter superficial, podemos encontrar en la trama algunas nociones relativas a la lucha por los derechos. En primer lugar, la acción transcurre en San Francisco, considerada una de las ciudades más liberales de los Estados Unidos -sino la más liberal-. Asimismo, el personaje de Matt Drayton interpreta a un editor de periódico reconocido en la ciudad entera por su amplia tolerancia y respeto por todo tipo de temáticas. Su mujer, Christina, también se destaca por su comprensión -entiende a su hija desde un principio- y el resguardo de los valores que la familia propugna por ejemplo, al echar a Hilary, su asistente en la Galería, representante de una aristocracia ultra-conservadora. Yendo aún más lejos, estas cualidades pueden transportarse a la pareja actoral: "Hepburn has solid liberal credentials; she was a progressive, a lifelong feminist. Tracy was more conservative, but he, too, was anti-racist" (Gordon y Vera, 2003, p. 87) [Hepburn tiene sólidas credenciales liberales; ella era una progresista, una feminista de toda la vida. Tracy era más conservador, pero él también era antirracista]. ${ }^{9}$ En segundo lugar, el film fue realizado poco tiempo después del abandono del Código de Producción Cinematográfico, conocido como Código Hays. Durante cuarenta años ciertos temas habían estado ausentes de las pantallas hollywoodenses, por lo que la incorporación del tópico del matrimonio interracial era toda una apuesta a la liberación. De hecho, Guess Who's Coming to Dinner muestra el primer beso interracial en pantalla. Empero, estos puntos sólo subrayan una aparente liberalidad y no un tratamiento crítico sobre los problemas del matrimonio interracial en los Estados Unidos.

El sentido subterráneo del film, que corrobora nuestra hipótesis, puede ser analizado en dos premisas: la tesis del negro con cualidades de blanco y la falsa tolerancia. En cuanto a la primera, Dr. Prentice, para poder ser el marido de una mujer blanca, es presentado como un superhéroe, una persona importante y respetable, amable y caballerosa, con una vastísima trayectoria académica. A tal punto es exagerada la composición del personaje que Prentice ha rechazado tener sexo con su novia antes de la boda. Cabe recordar que Sidney Poitier era una estrella ratificada por la audiencia blanca norteamericana del momento. Como bien expresa Ángel Rubio Moraga: "Poitier encarnará durante muchos años al negro educado e inteligente, hablando un inglés perfecto, elegantemente vestido y con unas maneras exquisitas en la mesa. Es, en definitiva, un negro que se comporta 'como un blanco'” (2004, p. 4)..$^{10}$ Por lo dicho, el tema del matri- 
monio interracial adquiere un significado connotado: la única posibilidad que dispone un hombre negro para casarse con una mujer blanca es convertirse en un ideal construido por la propia mentalidad blanca, y esto refiere al concepto de falsa tolerancia al cual aludimos. En este sentido, "the film really emphasizes how narrow the field of possibility is for black Americans" (Gordon y Vera, 2003, p. 95) [La película realmente enfatiza cuán estrecho es el campo de posibilidades para los estadounidenses negros]. Esta es entonces una de las formas en las que se manifiesta la supremacía del blanco. En relación al segundo rasgo, podemos aseverar que el discurso final de Matt viene a revalidar dicha supremacía. La aceptación última del hombre blanco, que permite superar las diferencias raciales, resolver el conflicto y recomponer la situación de equilibrio, es justamente eso: un privilegio del ser blanco sobre el cual el negro debería estar agradecido, pero que no apunta tanto a beneficiar al negro sino que habla más de la (falsa) tolerancia, la comprensión y los valores del blanco cuyo sentir, pensar y accionar se colocan siempre en el centro de atención. Esta disposición preferencial vislumbra una relación social de dominación y hegemonía.

Finalmente, a pesar de haber expresado que el tema de los Derechos Civiles era trabajado de forma transversal en este film ya que el matrimonio interracial no se aborda desde una postura crítica sino desde la supremacía blanca, hay sin embargo un personaje secundario que lleva la voz del activismo negro: Tillie, la mammy de la familia Drayton. Empero, su peso es mínimo, como lo es en realidad el de todas las mujeres del film. Ni mujeres ni negros; sólo triunfa el hombre blanco.

\section{La salvación es ficción: en relación a Mississippi Burning}

A diferencia del film analizado anteriormente, en este el contenido apunta directamente a la lucha por los Derechos Civiles, si bien algunas singularidades desbordan, tergiversan y manipulan la realidad de los hechos. El punto disparador del film está dado por un caso real: el 20 de junio de 1964, Michael Schwerner, Andrew Goodman y James Chaney llegaron a Mississippi como parte de un grupo de voluntarios del "Verano de la Libertad" que educaban y registraban electoralmente a los afroamericanos. Un grupo del Ku Klux Klan los asesinó y enterró en unas fosas ocultas en Filadelfia, una pequeña ciudad de Mississippi. Aunque las autoridades del lugar quisieron encubrir los hechos, seis semanas más tarde los cadáveres fueron hallados.

El año de producción de la película es 1988, y en una primera aproximación podríamos decir que el cine de Hollywood ha dado un salto en cuanto a un avance significativo -por ejemplo en relación al film Guess Who's Coming to Dinner- con respecto al tratamiento del negro y los Derechos Civiles: la presencia del negro se multiplica en la pantalla -no es sólo un personaje con cualidades superheroicas- y el tema racial es explícito y directo. Sin embargo, por un lado, los negros son descriptos como seres pasivos, que sufren y que son incapaces de tomar acción y luchar por cuenta propia. Por el otro, "the movie alleviates white guilt by suggesting that race prejudice is a thing of the past (...) and that fearless white saints will always emerge to fight for justice and equality for blacks" (Vera y Gordon, 2003, p. 45) [La película alivia la culpabilidad blanca al sugerir que los prejuicios raciales son cosa del pasado (...) y que los santos blancos valientes siempre surgirán para luchar por la justicia y la igualdad para los negros]. Estos santos blancosestán encarnados en la figura de los agentes del FBI. Por tal motivo, podemos afirmar que estamos nuevamente en presencia de una estrategia ideológica de auto-consagración del blanco, bajo la forma del mesías blanco salvador que distorsiona ampliamente la experiencia real de los acontecimientos.

Como bien sabemos, los verdaderos héroes de la lucha por los Derechos Civiles fueron, entre otros, Martin Luther King Jr., trabajadores y estudiantes negros del sur, y también estos tres jóvenes sobre los cuales el film aparenta centrarse, pero que sin embargo son asesinados al comienzo del relato. Esta estrategia narrativa, a partir de la cual no se nos permite conocer nada sobre los jóvenes puesto que mueren en la escena inicial, al tiempo que enmascara la verdadera lucha y tergiversa los hechos reales, modifica el punto de vista del film y el personaje focal del mismo, proponiendo una clara identificación con el noble heroísmo del FBI. En este sentido, la película privilegia "the perspective and position of majority white culture over the perspective and position of minority black culture" (Rocchio, 2000, p. 101) [La perspectiva y la posición de la cultura blanca mayoritaria por sobre la perspectiva y la posición de la cultura negra minoritaria].

En cuanto a los agentes, Ward es un liberal heroico 
del norte que sigue los estándares al pie de la letra, pero que en esta oportunidad -puesto que la acción transcurre en Mississippi- es un extranjero. Anderson, por el contrario, es un perdedor que se ha desempeñado tiempo atrás como sheriff de un pueblo chico dentro de Mississippi, aunque se destaca por su nobleza y bondad. Esta inclusión podría responder una vez más a una estrategia ideológica que intenta mostrar que no todos los blancos sureños son racistas enfervorecidos. Asimismo, al haber pertenecido de algún modo a esta ciudad, tiene un conocimiento mayor acerca de cómo actuar y qué métodos utilizar, y de este modo esas herramientas -algunas ilegales- son bien recibidas por el público ya que no se trata de un total extranjero sino de un insider cuyas cualidades se contraponen a la violencia, el racismo y el odio de los otros blancos del sur. De esta forma, Anderson seduce a la mujer de uno de los líderes del Klan y luego termina por irrumpir en el mismo ocasionando delaciones interiores; vehículo por el cual el FBI resuelve el caso.

Por otro lado, podríamos agregar dos cuestiones a propósito del FBI que sostienen nuestra hipótesis y que también nos aportan información complementaria acerca del contexto de producción del film. En primer lugar, el FBI estaba directamente en contra del Movimiento por los Derechos Civiles, no era amistoso con las minorías y tenía en la mira a Martin Luther King Jr. por relacionarlo con el comunismo y el terrorismo. El FBI era realmente un estandarte del privilegio blanco, donde prácticamente sólo podían pertenecer hombres blancos. De este modo, el protagonismo de la pareja de agentes Ward/Anderson, que suscita una clara identificación, permite el corrimiento, borramiento y ocultamiento de la verdadera historia afroamericana. En este sentido, el film toma la lucha contra el racismo desde una perspectiva para y por el hombre blanco. Es decir, "racism, perpetuated by whites, becomes a problem for whites to solve" (Rocchio, 2000, p. 108) [El racismo, perpetuado por los blancos, se convierte en un problema para que los blancos lo resuelvan]. En este punto, el mecanismo del film guarda cierta similitud con el planteado en Guess Who's Coming to Dinner, donde el racismo respondía a un problema de tolerancia del blanco que al final del relato se resolvía gracias a la acción propia del hombre blanco, relegando a un segundo plano el pensamiento y el accionar del hombre negro. En segundo lugar, el conflicto que se genera entre dos posturas disímiles -Ward/ Anderson- responde a un momento puntual de la historia norteamericana. A finales de los años ochenta se produjo un crecimiento de la burocracia federal, lo cual permitía el salto desde el ámbito local hacia una posición más significativa. A su vez, esta expansión puede notarse en el film en la gran cantidad de recursos que el gobierno dispone para el caso, hecho que por momentos se vuelve irrisorio y poco creíble, como por ejemplo la compra del hotel en el instante en que el dueño comienza a causar problemas, o la cantidad de federales requeridos para rastrillar el río.

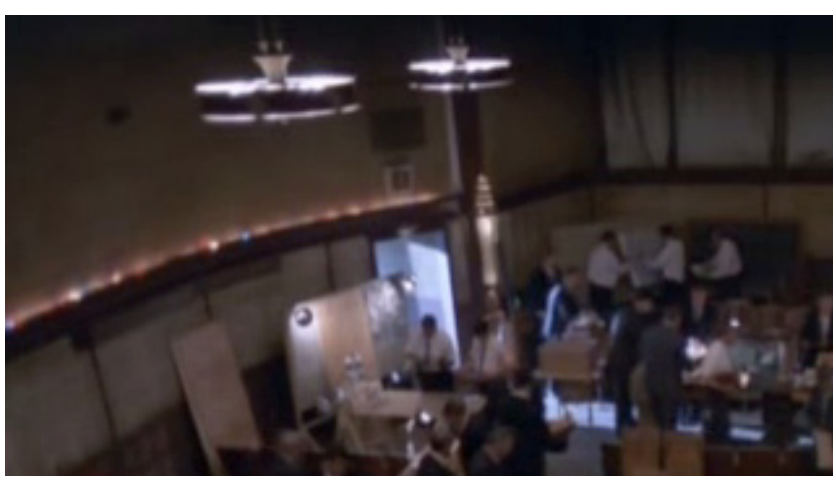

Por último, otro dato a destacar, y que nos posibilita realizar una comparación entre los tres films, es el modo en que se presenta el personaje femenino. En Guess Who's Coming to Dinner tanto Joanna como Chistina, Tillie o la madre de John, son personajes secundarios. La decisión y el poder lo tiene Matt, el hombre de la casa. En Mississippi Burning Mrs. Pell tiene una incidencia mayor en el desarrollo de las acciones, pero es el agente Anderson -el hombre blanco- el que la lleva a realizar ese salto en la consciencia. En el próximo apartado veremos el lugar que ocupa la mujer en The Help y la distinción entre la posición de la mujer negra y la mujer blanca.

Entonces, tanto el crimen temprano de los jóvenes activistas sobre los cuales no tenemos conocimiento alguno como la pasividad, el silencio y el miedo con que son caracterizados los personajes negros dentro del film, junto con el noble heroísmo de los agentes del FBI, que gracias a su intervención logran restablecer la armonía, demuestran una vez más la pretendida supremacía del ser blanco en el interior de una historia sobre la cual intentan ser dueños y protagonistas.

\section{El salto concientizador: acerca de The Help}

Si comenzáramos el análisis, como en los casos anteriores, con una primera aproximación superficial, deberíamos expresar que el avance en relación al tratamiento de los Derechos Civiles que devela el film resulta importante, comparándolo con los comentarios consumados a 
propósito de los otros dos films y teniendo en cuenta el año de producción de esta película. La lucha de los negros por sus derechos es el núcleo principal de la película y la gran mayoría de los personajes centrales no sólo son negros sino que son mujeres -en contraposición al espacio secundario que ocupaba la mujer en los dos films anteriores-. A pesar de ello, cierto resabio de supremacía blanca se hace presente en la estructura del relato.

Repasemos algunos elementos de la historia. Al igual que en Mississippi Burning la acción transcurre en Mississippi (Jackson, Mississippi), en pleno desarrollo del Movimiento por los Derechos Civiles (año 1962). Sin embargo, si tuviéramos que resumir el argumento en unas pocas líneas diríamos que The Help está centrada en la joven blanca Eugenia "Skeeter" Phelan, su relación con dos mucamas negras y la publicación de un libro que expone el racismo a través de la voz de las mucamas. En este sentido, y si bien el film comienza mediante una narración en over de una de las mucamas negras -cuya voz intermitente vuelve en diferentes momentos-, y registra a través del libro las historias de las mucamas y los maltratos y humillaciones que debían soportar por parte de sus patrones -mujeres blancas de la aristocracia-, el punto de vista focal está puesto sobre la joven periodista y escritora blanca. A diferencia de Guess Who's Coming to Dinner y Mississippi Burning aquí, como vemos, la mujer no es un personaje secundario sino central. Sin embargo, aunque la supremacía, el control y la decisión no está dada por el hombre blanco, el empuje concientizador será llevado a cabo por la mujer blanca. Es decir que en el fondo la lucha de la comunidad afroamericana, hecho medular en el film, sigue estando supeditada a la ayuda blanca. En cierta forma, y a pesar de los supuestos avances comentados, se reedita nuevamente la noción del mesías blanco salvador.

Empero, como dijimos, algunos elementos del relato colaboran en la construcción de esa máscara de pretendido progresismo en la conformación del tema; máscara que, frente a una visión atenta, devela aquello que desea ocultar. En primer lugar, recordemos que el personaje de la Mammy, si bien tenía un rol importante en los relatos clásicos, era un personaje secundario, destinado a permanecer inerte a lo largo de la historia; sin una identidad propia, sin transformación, siendo un fiel servidor del patrón blanco. ${ }^{11}$ En The Help, la Mammy advierte variaciones -al tratarse el film sobre mucamas en plural, en algunas oportunidades son sólo ello: mucamas-, conservando sólo en ciertos ejemplos las cualidades más significativas del estereotipo, como por ejemplo el carácter y la contextura física. Sin embargo, ellas sí tienen una historia personal y se constituyen en protagonistas del drama: Aibileen Clark tiene cincuenta años, ha pasado toda su vida cuidando niños blancos y recientemente ha perdido a su hijo. Al final del film, y luego de haber sido uno de los pilares de la lucha, su empleadora se deshace de ella. Minny Jackson, otra mucama, amiga de Aibileen, ha sido despedida unas cuantas veces y ha suscitado una reputación de conflictiva. Finalmente, deja a su esposo golpeador y se muda junto a sus hijos a la casa de Celia, su empleadora, cuyas características analizaremos luego. Como vemos entonces, las mucamas son sujetos que tienen una identidad -hijos, maridos, etc.- y cuyas vidas resultan modificadas al concluir el relato: una lucha ganada, finalización de una etapa laboral, asentamiento laboral, etc.

En segundo lugar, y en estrecha conexión con lo anterior, las mucamas negras accionan. A su vez, parecería que llevan adelante la acción principal: en la primera escena del film aparece Aibileen frente a cámara respondiendo preguntas a una persona de sexo femenino que toma nota y que está prácticamente fuera del cuadro -sólo observamos sus manos y escuchamos su voz-. Acto seguido, la voice over de Aibileen narra su propia historia. Podríamos entender este mecanismo como una estrategia de encubrimiento, puesto que quien escribe y hace las preguntas es Eugenia, verdadero punto focal del relato que luego será quien mueva los hilos de la historia. No obstante, sí es cierto que las mucamas tienen incidencia en el desenvolvimiento de los hechos, sea cual sea la fuente que motive su accionar. Ellas sufren, sí, pero no son pasivas al respecto. Aibileen es la primera que decide contarle a Eugenia sus historias de maltrato y humillaciones; Minny, reticente al comienzo, se suma luego y termina siendo crucial en la captación de otras mucamas, cuyos relatos son indispensables para la publicación del libro. Asimismo, Minny, toma venganza por el despido provocado por Hilli, preparándole un pie con sus excrementos.

En tercer lugar, las cualidades y los comportamientos de las mujeres blancas ricas están exagerados con el objetivo de marcar un fuerte contraste entre la maldad de estas y el amor, cariño y sufrimiento de las mucamas negras. De este modo, el espectador puede prestar una mayor empatía hacia Eugenia y también hacia Celia, ambas mujeres blancas que por diferentes motivos desencajan dentro de las normas de comportamiento y pensamiento habituales de la aristocracia sureña en la historia norteamericana. Por ejemplo, Hilli Holbrook presenta 
una iniciativa sanitaria para que los negros usen un baño separado, en el exterior de la casa, puesto que cree que pueden tener enfermedades diferentes a los de la gente blanca; y también se niega a darle un préstamo a Yule May, su mucama, para que su hijo pueda estudiar, a pesar de que esta propone trabajar gratis. A su vez, Hilli junto a Elizabeth arman un plan para echar a Aibileen, acusándola de haber robado un objeto de plata, a pesar de que Mae, la hija de Elizabeth se ha encariñado con Aibileen luego de tantos años de cuidado.

En cuarto lugar, podemos mencionar a Celia Foote y su marido Johnny. Ella es rica, pero ha quedado afuera de la sociedad de las damas aristocráticas por haber nacido en un una familia de trabajadores y por el simple hecho de que su marido había sido un ex novio de Hilli. Celia trata a Minny con respeto, es amorosa y se sienta a comer en la misma mesa. Al final, Celia y su marido agasajan a Minny con una gran cena y le piden que trabaje con ellos para siempre. Esta situación, si bien podría representar un claro elemento progresista, sirve en tanto mecanismo de equilibrio y apoyo en relación a la concientización que lleva adelante Eugenia. Es decir, responde a la necesidad de mostrar que no todas las mujeres blancas ricas maltratan a sus mucamas, en pos de que la exterior ayuda blanca hacia la lucha de los afroamericanos resulte más natural.

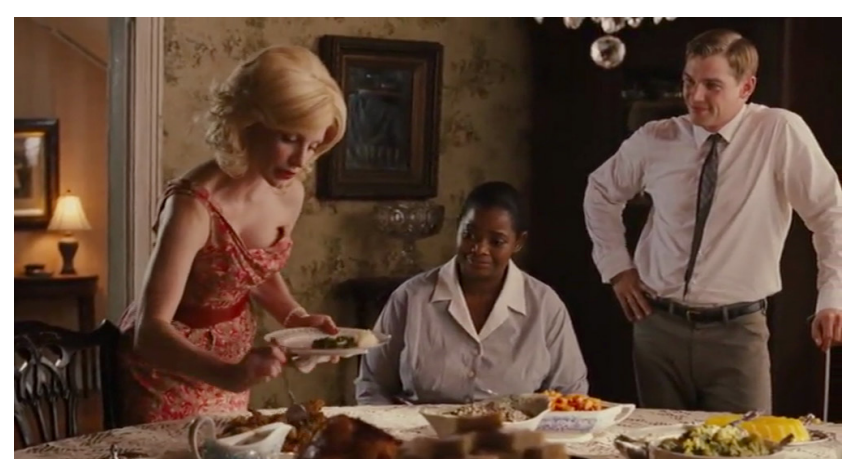

Por último, entonces, acotamos una reflexión más acerca de la verdadera protagonista, Eugenia. A diferencia de sus amigas ricas, ella no ha ido a la universidad a encontrar marido, se ha graduado y desea comenzar una carrera como escritora. Toma un primer trabajo como columnista y es en busca de colaboración para responder a unas tareas que entabla una relación con Aibileen. Luego, su disconformidad con el modo en que sus amigas tratan a las mucamas despierta su interés por recolectar el punto de vista de estas en torno a dichos hechos, y las incentiva a concretarlo. Es decir que, si bien la película postula a las mucamas como aquellos personajes centrales, advertimos que tanto la intención como la real concreción de este movimiento liberador dentro de la historia del film -el libro se publica gracias a las posibilidades que los estudios realizados por Eugenia le brindan- es impulsado por una mujer blanca, pseudo-liberal.

\section{Reflexiones finales}

La relación de blancos y negros en el cine de Hollywood data de los orígenes del séptimo arte. Ahora bien, la desigualdad de valores entre ambos presenta la misma fecha de inauguración. En concordancia con las políticas sociales y culturales de la Nación, la presencia del negro en la pantalla ha estado siempre marcada: blancos enmascarados para representar a los negros, en un principio; categorías estereotipadas y precisas; roles secundarios, etc. Esto se debe a que, en palabras de Gwendolyn Audrey Foster, "the cinema has been remarkably successful at imposing whiteness as a cultural norm" (2003, p. 2) [El cine ha tenido un éxito notable al imponer la blancura como norma cultural]. Y es justamente esta capacidad de la blancura para funcionar como el canon lo que le permite mantener una posición de privilegio, conformando un mundo imaginario a su medida que aparenta ser real pero que se concibe como un artificio. De este modo, el racismo puede rastrearse a lo largo de todo el desarrollo del cine norteamericano, desde los inicios hasta la contemporaneidad. Las aparentes evoluciones en la concepción de la trama y los personajes en relación al binomio blancos/negros, no son más que concesiones hipócritas a una audiencia que reconoce de forma (in)consciente la supremacía del hombre blanco. Este punto de vista, dominante y hegemónico, sostiene claramente que "whites are not of a certain race, they're just the human race" (Foster, 2003, p. 1) [Los blancos no son de una raza determinada, son simplemente la raza humana].

En el presente trabajo hemos intentado demostrar que este aparente progresismo en la forma de afrontar la temática de la lucha por los Derechos Civiles en el cine de Hollywood en diferentes etapas encierra y encubre una subtrama que pone a la luz la pretendida supremacía de ser blanco. En Guess Who's Coming to Dinner (Stanley Kramer, 1967) el contexto de producción del film mantiene una estrecha conexión con el Movimiento, más que la propia diégesis. No obstante, de forma superficial, intenta poner en escena las posibilidades de llevar adelante un matrimonio interracial. Ahora bien, queda al descubierto, después de realizar una lectura atenta, que 
la película dice más acerca del propio ser blanco que del verdadero problema interracial. En el análisis percibimos dos grandes núcleos que sostienen esta supremacía. Por un lado, el negro debe ser un superhombre con cualidades intelectuales y de personalidad sobresalientes en pos de permitirle casarse con una joven blanca. Por el otro, el hombre blanco, gracias a su tolerancia, es el que finalmente, con su bendición, posibilita el casamiento, resolviendo el conflicto; su propio conflicto.

Mississippi Burning (Alan Parker, 1988) toca de lleno la lucha por los derechos del afroamericano. Sin embargo, de entrada, el film coloca a los dos agentes del FBI no sólo en tanto protagonistas del relato sino, mediante estrategias narrativas e ideológicas precisas, como los verdaderos héroes del Movimiento por los Derechos Civiles. Ward y Anderson responden a la noción del mesías blanco salvador que viene a solucionar un conflicto que toman como propio, sin reconocer a los participantes reales y verdaderos responsables de la lucha. El film suscita una fuerte identificación con los agentes borrando rápidamente de escena a los jóvenes liberales -estos son asesinados en la primeras imágenes, sin permitirnos conocer profundamente sus pensamientos y comportamientos-, caracterizando a los negros como personas pasivas, con miedo e incapaces de salir adelante por sus propios medios, y postulando al FBI como el gran salvador que utiliza todos los recursos habidos y por haber -algunos imposibles, otros ilegales- para resolver de forma contundente la situación de conflicto. Es interesante también, al igual que en el film anterior, la presencia secundaria del personaje femenino.

En The Help (Tate Taylor, 2011) el avance parece ser claro, y de hecho lo es. Empero, en cierto punto se mantiene el resabio del poderío blanco. Aquí, tanto la lucha llevada a cabo por los afroamericanos como la presencia de la mujer con un rol protagónico, son dos hechos centrales. La mucama negra tiene su propia historia, acciona y sufre transformaciones. Sin embargo, las estrategias narrativas nuevamente enmascaran el punto de vista ideológico. Si bien Aibileen y Minny tienen papeles cruciales, el personaje focal del film es Eugenia, una mujer blanca que gracias a sus deseos, intenciones y habilidades intelectuales incentiva a las mucamas a contar sus historias de humillaciones y maltratos, las cuales finalmente son publicadas en un libro. Es decir que el progresismo en la concepción de la mujer negra como protagonista de la lucha devela en definitiva el acto concientizador llevado a cabo por una mujer blanca, verdadera conductora de los hilos de relato.

En este sentido, pudimos observar cómo a través de diversas modalidades y tácticas narrativas, ideológicas y políticas, el punto de vista adoptado en los films norteamericanos que trabajan sobre temáticas relacionadas con la lucha por los Derechos Civiles del afroamericano, tanto en épocas pasadas como actuales, mantiene un claro contenido racista. Creemos que, como bien expresa Foster, "whiteness is a form of social control that erupts and continues to be reinvented in cinema" (2003, p. 26) [La blancura es una forma de control social que eclosiona y continúa reinventándose en el cine]. La blancura está presente en todo el cine de Hollywood como una categoría que pretende ser invisible e indivisible, inclasificable y no caracterizada, pero que paradójicamente tiene el afán de perpetrarse como una fuerza omnisciente y omnipotente.

Para finalizar, resulta pertinente plantear la necesidad de multiplicar -desde la Teoría y la Historia del cine- trabajos analíticos que brinden un recorrido similar al aquí desarrollado. Es decir, que puedan manifestar aquellas estrategias encubridoras y que estén en condiciones de dar cuenta tanto sobre las lecturas superficiales como también en torno a los significados profundos que contienen el verdadero núcleo ideológico del film y que permiten escribir una historia del cine reflexiva y atenta. Esta premisa, de algún modo u otro, debe llevarnos a re-pensar la blancura en el cine-y por qué no, a escala social y cultural- desde un enfoque netamente ético y político, con el objetivo de ponerla al descubierto y concluir en -a través de las palabras iluminadoras de Foster"(...) the recognition of whiteness as a performed construct" (2003, p. 4) [(...) el reconocimiento de la blancura como una construcción intencional].

\section{Referencias}

Bogle, D. (1994). Toms, conos, mulatotes, mammies and bucks. An interpretative history of blacks in American films. Oxford: Roundhouse.

Chambers, R. (1996). “The Unexamined”, en Minnesota Review, № 47, Otoño 1996 (New Series).

Dyer, R. (1997). “The matter of Whiteness” y “Coloured white, not coloured”, en White. New York: Routledge.

Fonseca, M. y Jerrems, A. (2012). “Pensamiento decolonial: ¿Una 'nueva’ apuesta en las Relaciones Internacionales?”, en Relaciones Internacionales, $\mathrm{N}^{\circ} 19$. Universidad Autónoma de Madrid. 
Foster, G. A. (2003). "Performing Whiteness" y "Inventing Whiteness", en Performing Whiteness. New York: State University of New York Press.

Freud, S. (1930) [1976]. “El malestar en la cultura”, en Obras Completas. Buenos Aires: Amorrortu Editores. Tomo XXI.

Gordon, A. M., y Vera, H. (2003). “The Beautiful White American: Sincere Fictions of the Savior” y "Racism as a Project: Guess Who's Coming to Dinner”, en Screen Saviors: Hollywood Fictions of Whiteness. Lanham: Rowman \& Littlefield.

Gramsci, A. (1970). “Concepto de ideología”, “La ciencia y las ideologías 'científicas”, en Introducción a la filosofía de la praxis. Barcelona: Península.

Herrnstein, R. J. y Murray, C. (1994). The bell curve: intelligence and class structure in American life. New York: The Free Press.

Michel Fariña, J. J. (2002). Ética: un horizonte en quiebra. Buenos Aires: Eudeba.

Quijano, A. (2007). “Colonialidad del poder y clasificación social”, en Castro-Gómez, S. y Grosfoguel, R. (Eds.) El giro decolonial. Reflexiones para una diversidad epistémica más allá del capitalismo global. Bogotá: Siglo del Hombre Editores.

Rocchio, V. F. (2000). “Mississippi (and history) Burning”, en Reel Racism: Confronting Hollywood's Construction of Afro-American Culture. Boulder, Colorado: The Perseus Books Group.

Rubio Moraga, A. L. (2004). “Evolución del racismo en el cine norteamericano. De David W. Griffith a John Singleton”, en Creando cine, creando historia. La representación cinematográfica de ideas y movimientos sociales. Madrid: Servicio de Publicaciones de la Facultad de Ciencias de la Información de la Universidad Complutense de Madrid.

Tuñón, A. H. (1993). Reflexión ética sobre el racismo y la xenofobia. Fundamentos teóricos. Madrid: Editorial Popular-JCI.

\section{Filmografía mencionada}

Guess Who's Coming to Dinner (Stanley Kramer, 1967)

Mississippi Burning (Alan Parker, 1988)

Uncle Tom's Cabin (Edwin S. Porter, 1903)

The Birth of a Nation (David Wark Griffith, 1915)

The Help (Tate Taylor, 2011)

1 Dicha tendencia originada en las reflexiones de Herbert Spencer tuvo diversas repercusiones a lo largo de la historia. Contemporáneamente Richard J. Herrnstein y Charles Murray (1994) reivindicaron particularmente la supremacía del hombre blanco a través del carácter intelectual genético. Desde esta concepción, el supuesto éxito de unos y la pobreza de otros estaba directamente vinculado al coeficiente intelectual.

2 En "El Malestar de la cultura" (1930) [1976] Sigmund Freud atribuye las bases del racismo al "narcisismo de las pequeñas diferencias".

3 Todas las traducciones de textos cuyo idioma original es el inglés han sido realizadas por J.C.

4 Resulta pertinente señalar que hacia finales de la década del ochenta apareció una generación de cineastas pertenecientes a la minoría afroamericana, como Spike Lee y John Singleton entre otros, que abordaba las problemáticas que sufría dicha comunidad. No obstante, esta posición enunciativa suscita nuevos interrogantes que no pueden ser analizados en este ensayo bajo las premisas aquí delineadas.

5 Este film, de gran éxito de público, tuvo una recaudación de más de cincuenta y seis millones de dólares, y ganó dos premios Óscar en las categorías de mejor actriz principal (Katharine Hepburn) y mejor guion original. Asimismo, obtuvo ocho nominaciones en las categorías de mejor película, mejor director, mejor actor principal (Spencer Tracy), mejor actor de reparto (Cecil Kellaway), mejor actriz de reparto (Beah Richards), mejor dirección artística, mejor música y mejor montaje.

6 La película percibió más de treinta y seis millones de dólares, ganó el premio Óscar a la mejor fotografía y fue candidata a seis premios más, entre ellos, a mejor director. Posteriormente recibió galardones en los Premios BAFTA y en el Festival Internacional de Cine de Berlín.

$7 \quad$ El film fue candidato al Óscar como mejor película y mejor actriz, y obtuvo la estatuilla en el rubro de mejor actriz de reparto (Octavia Spencer). Luego de su segunda semana en exhibición la película escaló a la primera posición del ranking estadounidense. Solamente en los Estados Unidos la recaudación fue de casi ciento setenta millones de dólares.

8 Entendemos el concepto de ideología desde el punto de vista gramsciano, en tanto un sistema de ideas determinado o una concepción/visión de mundo particular que subyace en las diferentes actividades de la vida humana, incluyendo claro está, el arte 
(Gramsci, 1970). Ahora bien, resulta necesario articular dicha noción con otro término acuñado por el pensador italiano que es el de hegemonía, o mejor dicho bloque hegemónico. En este sentido, el poder de las clases dominantes sobre las clases sometidas no radica únicamente en el control del aparato represivo del Estado, ni tampoco en el poder de coerción política y económica, sino que precisamente está anclado en una begemonía cultural que dichas clases consiguen ejercer sobre las clases dominadas a través del control de la religión, la educación y la comunicación -entre otras mediaciones-, logrando un consenso que se vivencia como una experiencia natural. En definitiva, es esta perspectiva la que permite comprender las premisas ideológicas que una industria del cine dominante como Hollywood pretende transmitir a sus audiencias.

9 De esta forma es posible observar cómo opera el texto-estrella en la conformación de la diégesis dentro de la industria del cine. La vida personal de los actores se funde en la construcción de los personajes, lo cual permite afianzar y enfatizar ciertos rasgos sociales y culturales. El star-system se convirtió en una estrategia tanto comercial como ideológica.

10 Esta representación del negro atravesada por rasgos que devienen del estereotipo blanco de clase media denota aquello que, dentro de la teoría crítica decolonial, se comprende por colonialidad del poder. En palabras de Melody Fonseca y Ari Jerrems, esta "se entiende como un proceso histórico constitutivo y un sistema de dominación occidental que incluye la opresión económica, epistémica y racial de grupos subalternos" (2012: 105). Para la teoría decolonial las clases sociales y las relaciones de poder no se conforman como estructuras cerradas sino que se erigen como discontinuas, conflictivas y cambiantes. Esta "heterogeneidad de la clasificación social” (Quijano, 2007: 115) es la que posibilita deconstruir el sustrato colonial. Dicho pensamiento crítico en torno al colonialismo racista encuentra una base sólida en los escritos de Franz Fanon, principalmente en su famoso ensayo Les Damnés de la terre (1961).

11 En este punto es necesario hacer una mención a la exclusión y la marginación económica que conlleva el racismo, puesto que sus fundamentos originarios son eminentemente económicos: el esclavismo. Es decir que la discriminación racial no sólo implica un embate contra las libertades políticas y culturales de las minorías, sino que asimismo evidencia la restricción del pleno acceso al mercado laboral que estas sufren. En el film analizado esta situación de base es suavizada o escondida a partir del supuesto empoderamiento que las mucamas negras consiguen a lo largo del relato. 